\title{
Modal analysis of prestressed draft pad of freight wagons using finite element method
}

\author{
Sachin Sudhakar Harak • Satish Chand Sharma • \\ Suraj Prakash Harsha
}

Received: 15 September 2014/Revised: 4 November 2014/Accepted: 7 November 2014/Published online: 25 November 2014 (C) The Author(s) 2014. This article is published with open access at Springerlink.com

\begin{abstract}
The present work intends to investigate dynamic behaviour of draft gear using finite element method. The longitudinal force that the draft gear absorbs usually leads to the failure of its components, especially, the load bearing draft pads. Dynamic behaviour of an individual draft pad and a draft gear is determined and characterized with exciting frequencies and corresponding mode shapes. The effect of compressive prestress load on the dynamic behaviour of an individual draft pad is also determined as the draft pads in assembled state are under constant axial compressive force in the draft gear. The vibration characteristics of individual draft pad are compared with draft pads that are part of draft gear. The modal analysis gives us a basis for subjecting a draft pad to higher frequency loading for determining its fatigue behaviour.
\end{abstract}

Keywords Draft gear - Draft pad - Prestress - Natural frequency $\cdot$ Mode shapes $\cdot$ Finite element method

\section{Introduction}

In longitudinal train dynamics, draft gear is the most important component of the autocoupler. The autocoupler with friction type draft gear is the most common wagon connection in the Australian and North American freight system [1]. Similar autocouplers with draft gear are also used in the Indian freight system and their adoption in the freight system can be traced back in the early 1960s. Mark-50 was adopted in 1963, RF-361 was adopted in 1965 and SL-76 was

S. S. Harak $(\bowtie) \cdot$ S. C. Sharma · S. P. Harsha

Vibration and Noise Control Lab., Mechanical and Industrial

Engineering Department, Indian Institute of Technology,

Roorkee 247667, Uttarakhand, India

e-mail: sachin.s.harak@gmail.com adopted in 1977. Being an important part of the autocoupler system, the draft gear serves to absorb energy generated during the normal starting and braking of the freight railway wagon system and also during different train handling conditions, thus avoiding damage and failure of the coupling system. It thus functions as a passive vibration isolator to control and absorb high amplitude forces thereby avoiding damage to laden goods. The frequency of this longitudinal force depends on the train running condition and varies continuously.

The longitudinal force that the draft gear absorbs usually leads to the failure of its components, especially, the draft pads. Garg and Dukkipati [2] specified the problems caused by longitudinal forces and attributed the failure of draft gears due to excessive longitudinal draft forces. Initial work on longitudinal train dynamics was aimed towards reducing longitudinal oscillations in passenger train. Work done in this context involved measurement and simulation of in-train forces to reduce longitudinal oscillations [3]. The relation between lateral coupler force components and wheel unloading were studied by El-Sibaie [4] and a new method was proposed for evaluating the curving stability of any freight railway car under buff and draw conditions. Chen [5] proposed a mathematical model to calculate transient responses of the coupler, whereas McClanachan et al. [6] conducted experiments to determine the occurrences of coupler impacts combined with pitching motions in the wagon body. Then these interactions were simulated using NUCARS, ADAMS/Rail and a train-wagon interaction model. Cole and Sun [7] evaluated fatigue life of autocoupler systems with and without self-locking features of the draft gear for three types of wagon connection coupling systems. Nasr and Mohammadi [8] studied the effect of train braking delay time on train longitudinal dynamics. They carried out simulations for three different 
cases of long, medium and short brake application times for three different train forward velocities.

In this article, the dynamic behaviour of draft pad and draft gear is investigated using finite element method. The draft gear consists of six draft pads which are assembled in series (one above another) and are always under a constant axial compressive prestress in unloaded condition. Prestress influences the values of the stiffness matrix by causing stress stiffening and affects the response frequencies of the system thus impacting its modal responses [9]. The draft pad consists of a rubber compound/elastomer along with two steel plates. The modal behaviour of draft pad and draft gear assumes significance as it is necessary to identify frequencies at which fatigue failure of draft pads can occur. The vibration characteristics of the draft pad and the draft gear for the first 15 modes have been determined using finite element method. The vibration excitation of an individual draft pad has been compared with the dynamics of draft pads in the draft gear for identifying various frequencies for a given mode shape.

\section{Dynamic analysis of draft pad}

\subsection{FE analysis}

For a dynamic system, the general form of equation of motion is

$m \ddot{x}+c \dot{x}+k x=f(t)$.

Modal analysis determines the natural frequencies and mode shapes of a continuous structure. Thus, modal analysis helps in determining vibration characteristics of any system. In finite element solution, the differential equation of motion is discretized into a number of finite element equations which form a system of algebraic equations to be solved: $[\mathbf{K}]\{\mathbf{u}\}=\{\mathbf{F}\}$, where $[\mathbf{K}]$ is the stiffness matrix, $\{\mathbf{u}\}$ is the nodal displacement vector and $\{\mathbf{F}\}$ is the applied load vector. These equations are solved by finite element package ANSYS [10].

For a free vibration analysis, the natural frequencies $\left(\omega_{i}\right)$ and the mode shapes $\left(\phi_{i}\right)$ are determined using following relation: $\left([\mathbf{K}]-\omega_{i}^{2}[\mathbf{M}]\right)\left\{\phi_{i}\right\}=0$ [11]. For the prestressed modal analysis, the stress field is taken into account by modifying the stiffness matrix $[\mathbf{K}]$. While evaluating the mode shapes, the material is assumed to behave linearly elastic neglecting non-linearities, damping is not included, and no excitation of the structure is assumed.

\subsection{Model for modal analysis}

For vibration-based analysis, which is model dependent, an accurate model is important. FEM has been used for determining the mode shapes and natural frequency of continuous system like the freight wagon [12]. Threedimensional models of draft pad and draft gear are created using Solidworks and exported to ANSYS environment for numerical analysis.

\subsubsection{Individual draft pad}

The draft pad (RF-8) is illustrated through Fig. 1. Such pads serve as rubber springs in "RF-361" model of draft gears manufactured by Miner Enterprises Inc., USA, and are used in freight wagons autocoupler of Indian Railways. Each RF8 pad has ultra-high capacity natural rubber spring package to absorb the high longitudinal forces arising due to operations like acceleration and/or braking and also due to changes in track topography. This rubber compound/elastomer is sandwiched between two steel plates and perfectly bonded to them. The material properties of steel are-modulus of elasticity: $200 \times 10^{9} \mathrm{~N} / \mathrm{m}^{2}$, Poisson's ratio: 0.30 and material density: $7,850 \mathrm{~kg} / \mathrm{m}^{3}$. The rubber compound/elastomer has modulus of elasticity: $21.946 \times 10^{6} \mathrm{~N} / \mathrm{m}^{2}$, Poisson's ratio: 0.4970 and material density: $1,220 \mathrm{~kg} / \mathrm{m}^{3}$. The mechanical properties such as modulus of elasticity and Poisson's ratio of rubber compound/elastomer are obtained from experimental data. Experimental data refers to stressstrain plot obtained for an individual draft pad from compression test conducted in-house. MCalibration software has been used to derive the mechanical properties from this experimental plot. In general, the elastomer being used is vulcanized natural rubber with a hardness value of 75 on the Shore hardness scale (A scale). The rubber compound/elastomer under consideration is also described by its tensile strength and tear strength. Typical values are 180 and $40 \mathrm{~kg} /$ $\mathrm{cm}^{2}$, respectively. A maximum compression set of $25 \%$ at $70{ }^{\circ} \mathrm{C}$ for $24 \mathrm{~h}$ is also taken into consideration for accommodating geometric changes. The boundary conditions are: all nodes at the outer surface of bottom plate are fixed and the prestress pressure load is applied at outer surface of top plate.

\subsubsection{Draft gear}

Figure $2 \mathrm{a}$ illustrates three-dimensional view and Fig. $2 \mathrm{~b}$ presents sectional view of draft gear. The various components of the draft gear (RF-361) under consideration are draft pads (six in numbers) with top follower, shoes (three in numbers)

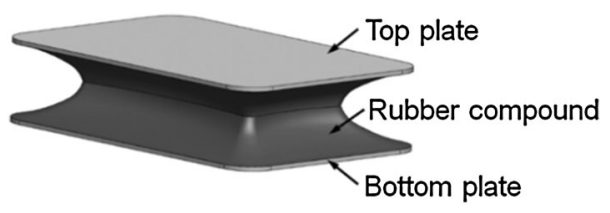

Fig. 1 Three-dimensional representation of typical draft pad (RF-8) 
(a)

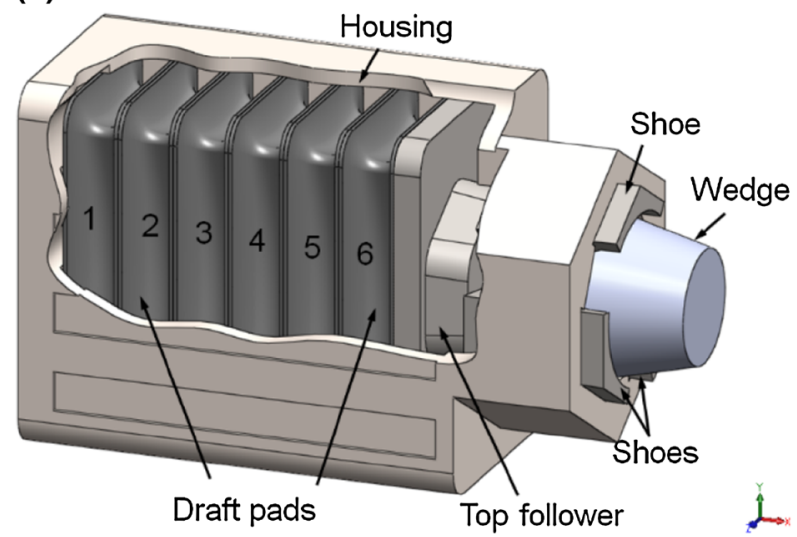

(b)

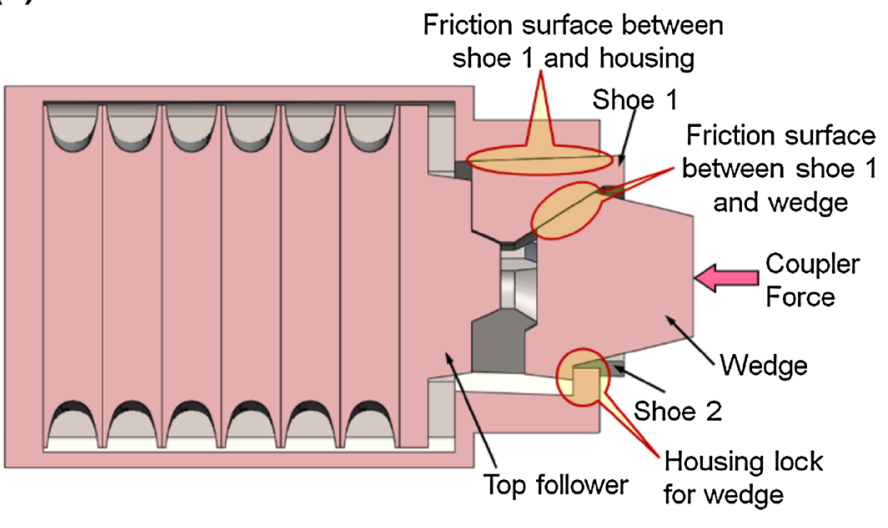

Fig. 2 Draft gear unit a three-dimensional representation and $\mathbf{b}$ sectional representation

and a wedge. All these components are assembled in a housing with the three shoes arranged circumferentially around the wedge. The rubber springs absorb the longitudinal (coupler) forces applied on the draft gear. The wedge and shoes operate between the top follower and the draft gear housing. The applied forces reach the rubber springs/draft pads only after overcoming the friction in two stages. In stage one, friction is provided by the surface contact between the wedge and the shoes. In stage two, friction is provided by surface contact between shoes and draft gear housing as illustrated in Fig. 2 b. The top follower provides support to the shoes. In both the stages, the friction between the components, i.e. wedge and shoes; shoes and housing, damps out the shock before the rubber springs/draft pads actually absorb the longitudinal force(s).

It means that the wedge and shoes act as shock damper and the applied force is then transferred to the rubber springs/draft pads. Each rubber spring/draft pad consists of elastomeric material sandwiched between two metal plates. Advantage of using draft gear having such damping effect is that impact energy on the couplers can gradually be absorbed by all the couplers. This results in lower coupler force in leading wagons. The height of a single draft pad prior to assembly is $67.2 \mathrm{~mm}$. In assembled condition the effective height of a single draft pad is $50 \mathrm{~mm}$. The material properties taken are same as those in Sect 2.2.1. The boundary conditions are taken as: all nodes at the bottom surface of the housing are fixed and the prestress pressure load is applied at outer surface of the wedge.

\section{Results}

The natural frequencies of an individual draft pad as illustrated in Fig. 3 for the first five modes are obtained using finite element package (ANSYS) and presented in
Table 1. As the first five frequencies are observed to be dominating, hence they are considered. These values are obtained under free stress condition.

These first five mode shapes of an individual draft pad are presented in Fig. 3. The draft pad as illustrated in Fig. 1 consists of three components, viz. top plate, rubber compound and bottom plate. All these three components are bonded together and behave as a single unit. Since the bottom plate is fixed, the motion of rubber compound and top plate describes each mode shape. The origin of the coordinate system is located at the geometric centre of the pad. The triad helps in visualizing the axes orientations. Accordingly, it is seen that

- The first mode shape shown in Fig. 3a describes oscillatory (angular) motion of the rubber compound and top plate about $x$-axis of the draft pad.

- The second mode shape illustrated in Fig. 3b shows oscillation of the rubber compound and top plate about $y$-axis. However, the $y$-axis about which the oscillation occurs does not coincide with the draft pad $y$-axis but passes through the base plate of draft pad.

- The third mode shape in Fig. $3 \mathrm{c}$ describes oscillation of the rubber compound and top plate about $z$-axis. The $z$ axis in this case also does not coincide with the draft pad $z$-axis, but passes through the base plate of draft pad.

- The fourth mode shape shown in Fig. 3d shows oscillation of the rubber compound and top plate about $y$-axis. The $y$-axis in this case is contained by the top plate as is evident from the colour code.

- The fifth mode shape illustrated in Fig. 3e indicates oscillatory motion of the rubber compound and top plate about $z$-axis. This $z$-axis passes through the top plate as is evident from the colour code.

The natural frequencies of the draft gear are also evaluated in a similar manner. These natural frequencies are 
(a)

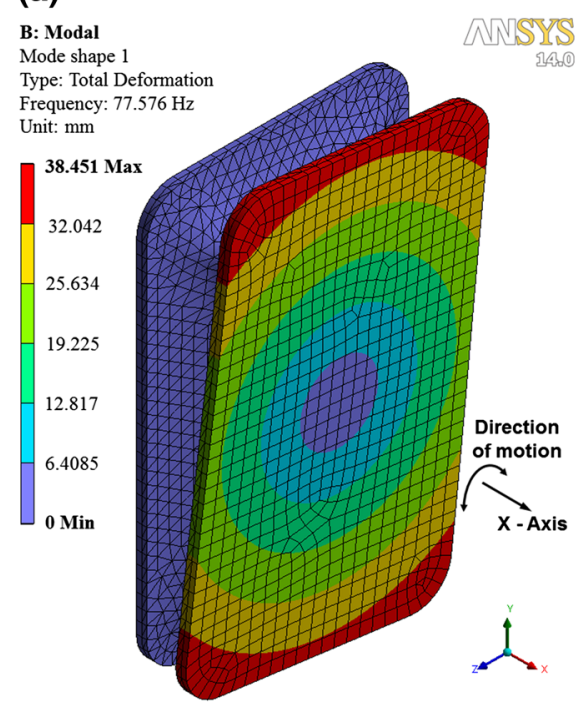

(c)

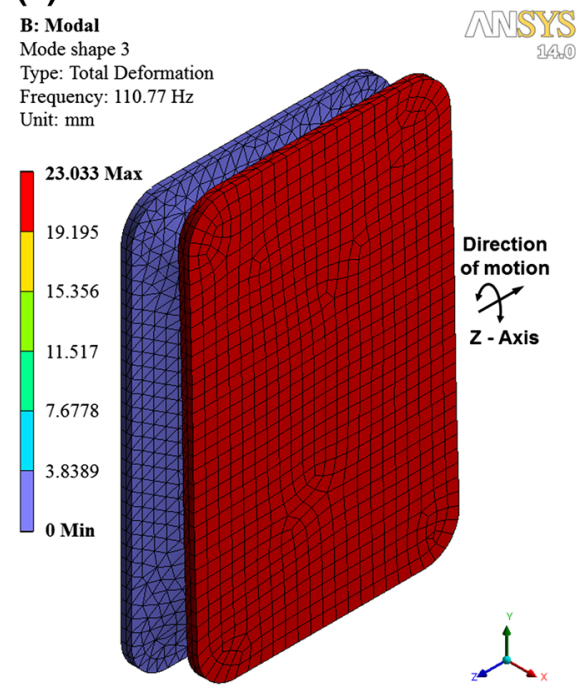

(b)

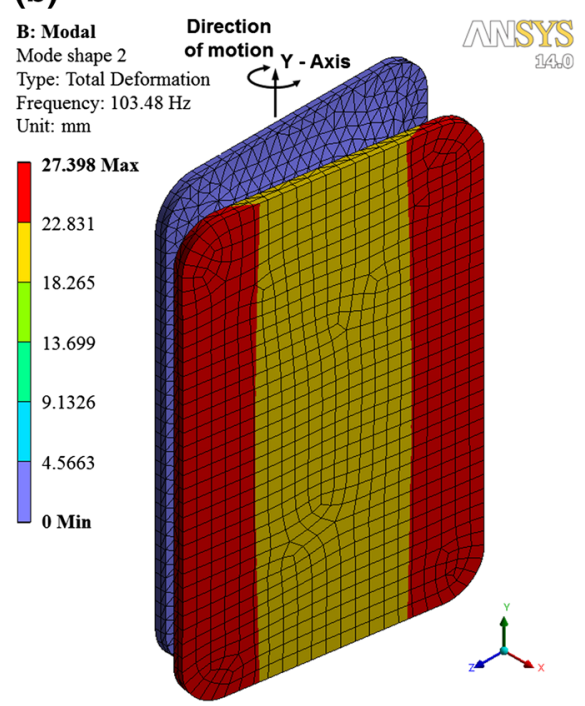

(d)

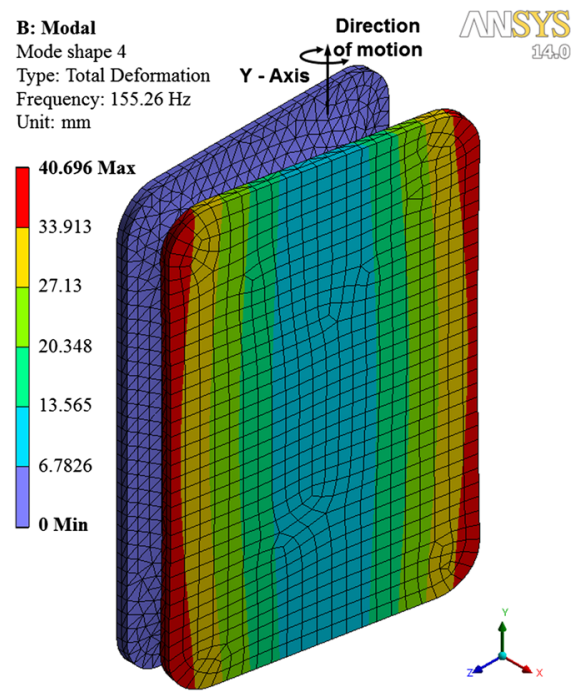

(e)

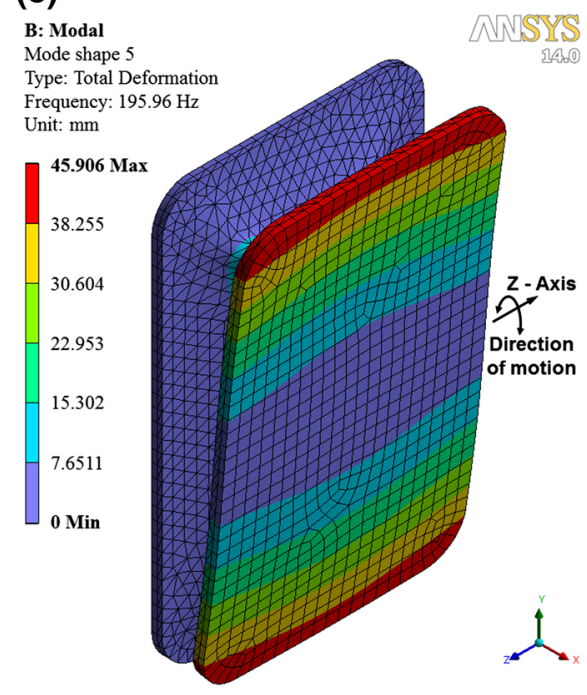

Fig. 3 Mode shapes of draft pad for a first, b second, $\mathbf{c}$ third, $\mathbf{d}$ fourth and e fifth natural frequency 
Table 1 Natural frequencies of an individual draft pad in $\mathrm{Hz}$

\begin{tabular}{llllll}
\hline Mode & 1 & 2 & 3 & 4 & 5 \\
\hline Frequency & 77.57 & 103.48 & 110.77 & 155.26 & 195.96 \\
\hline
\end{tabular}

obtained under prestress condition and are presented in Table 2.

A comparison of the mode shapes of each draft pad in the draft gear with mode shapes of an individual draft pad is done. It is observed that first five mode shapes of the individual draft pad are dominating the behaviour of each draft pad in the draft gear for all 15 mode shapes of the draft gear. This is because the draft pads housed in the draft gear have their own individual behaviour which cumulatively results in different mode shapes of the draft gear. These mode shapes of draft gear as such have no resemblance with mode shapes of an individual draft pad.

Figure 4 describes the first mode shape of a draft gear with prestress condition. The draft gear housing is very stiff as compared to draft pad and thus has a very poor modal response. Hence it has been hidden in this view. Modal behaviour of each draft pad is presented separately. It is seen that all the draft pads oscillate about the longitudinal $(x)$ axis of draft gear. Each draft pad exhibit modal behaviour close to its first modal shape. Since, the modal behaviour is symmetrical at the interface of third and fourth pad, hence only modal behaviour of the first three draft pads is presented in the illustration.

A general description of all the remaining mode shapes of draft gear is also necessary to establish the correlation between the mode shapes of draft pad and draft gear. For the second mode of the draft gear, linear displacement of the interface between pad 3 and pad 4 in lateral $(z)$ direction is observed causing the draft pads to exhibit modal behaviour close to its second mode shape. The third mode shows linear displacement of the interface between pad 3 and pad 4 in vertical $(y)$ direction causing the draft pads to exhibit modal behaviour close to its third mode shape. For the fourth mode shape, the interface between pad 3 and pad 4 remains fixed and the interfaces between pads 1 and 2, 2 and 3 and interfaces between pads 4 and 5, 5 and 6 oscillate about longitudinal $(x)$ axis in opposite sense. As a result, modal behaviour corresponding to the first mode shape of

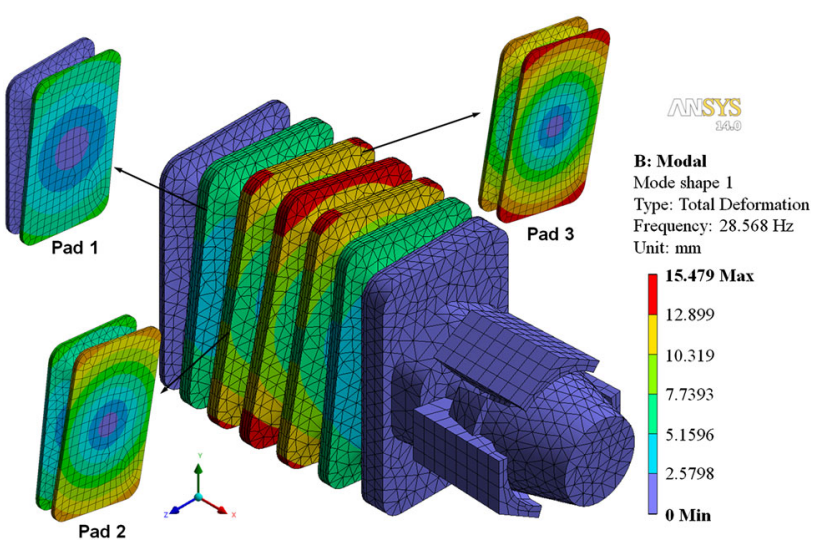

Fig. 4 First mode shape of a draft gear

draft pad is observed in some draft pads. Fifth mode shape shows oscillation of the interface between pad 3 and pad 4 about vertical ( $y$ ) axis. The results is that some draft pads exhibit second modal behaviour while some exhibit fourth modal behaviour of individual draft pad.

Sixth mode shape shows oscillation of the interface between pad 3 and pad 4 about lateral ( $z$ ) axis. As a result some draft pads exhibit third modal behaviour of individual draft pad. In the seventh mode shape, interfaces between pads 2 and 3, 4 and 5 remains fixed and interfaces between pads 1 and 2, 3 and 4, and 5 and 6 oscillate about longitudinal $(x)$ axis causing every single pad to execute motion in accordance to first mode shape. The eight mode shape of draft gear is oscillation of all draft pad interfaces about lateral $(z)$ axis. This oscillation results in fifth mode shape for all pads. For the ninth mode shape of draft gear, the interface between pads 3 and 4 remains fixed while the adjacent interfaces (i.e. interface between pads 1 and 2, 2 and 3 and interfaces between pads 4 and 5, 5 and 6) oscillate in opposite direction. This mode thus causes all pads to behave in accordance to first mode shape. For the tenth mode shape of draft gear, interface between pads 2 and 3 and pads 4 and 5 oscillate between about vertical (y) axis in opposite phase. The resulting effect is that all pads execute second modal behaviour.

For the eleventh mode shape, all pad interfaces oscillate about vertical $(y)$ axis in same phase and the resulting motion is in confirmation to the fourth modal shape. For

Table 2 Natural frequencies of draft gear under prestress load

\begin{tabular}{llllllllr}
\hline Mode no. & 1 & 2 & 3 & 4 & 5 & 6 & 7 & 8 \\
\hline Frequency (Hz) & 28.56 & 34.53 & 38.97 & 55.58 & 65.33 & 72.81 & 79.36 & 96.47 \\
\hline Mode no. & 9 & 10 & 11 & 12 & 13 & 14 \\
\hline Frequency (Hz) & 98.16 & 100.53 & 101.58 & 110.38 & 110.82 & 121.99 & 135.08 \\
\hline
\end{tabular}


the twelfth mode shape all adjacent pad interfaces oscillate about longitudinal $(x)$ axis in opposite direction causing each pad to follow first modal behaviour. For the thirteenth mode shape the interface between pads 2 and 3 and pads 4 and 5 oscillates about the lateral $(z)$ axis. As a result all pads execute motion in accordance to the third modal shape. For the fourteenth mode shape, all pad interfaces move linearly in the longitudinal direction. This is the only mode in which no pad behaviour confirms to any of the first five modes. In the fifteenth mode shape the interface between pads 3 and 4 oscillates about the vertical $(y)$ axis while interfaces between pads 2 and 3 and pads 4 and 5 move linearly in opposite phase in the lateral $(z)$ direction.

Table 3 Correlation between mode shapes and natural frequencies of an individual draft pad and draft gear

\begin{tabular}{|c|c|c|c|}
\hline \multirow{2}{*}{$\begin{array}{l}\text { Individual draft } \\
\text { pad } \\
\text { Mode no. }\end{array}$} & \multicolumn{3}{|c|}{ Draft gear } \\
\hline & $\begin{array}{l}\text { Pad } \\
\text { no. }\end{array}$ & $\begin{array}{l}\text { Similar } \\
\text { mode no. }\end{array}$ & $\begin{array}{l}\text { Corresponding } \\
\text { frequency }(\mathrm{Hz})\end{array}$ \\
\hline \multirow[t]{3}{*}{1} & 1,6 & $\begin{array}{l}1,4,7,9, \\
12\end{array}$ & $\begin{array}{l}28.56,55.58,79.36,98.16 \\
\quad 110.38\end{array}$ \\
\hline & 2,5 & $1,7,9,12$ & $28.56,79.36,98.16,110.38$ \\
\hline & 3,4 & $4,7,9,12$ & $55.58,79.36,98.16,110.38$ \\
\hline \multirow[t]{3}{*}{2} & 1,6 & $\begin{array}{l}2,5,10 \\
15\end{array}$ & $34.53,65.33,100.53,135.08$ \\
\hline & 2,5 & 10,15 & $100.53,135.08$ \\
\hline & 3,4 & $\begin{array}{l}2,5,10 \\
15\end{array}$ & $34.53,65.33,100.53,135.08$ \\
\hline \multirow[t]{3}{*}{3} & 1,6 & $3,6,13$ & $28.56,72.81,110.82$ \\
\hline & 2,5 & 3,13 & $28.56,110.82$ \\
\hline & 3,4 & 3,13 & $28.56,110.82$ \\
\hline \multirow[t]{3}{*}{4} & 1,6 & 11 & 101.58 \\
\hline & 2,5 & 5,11 & $65.33,101.58$ \\
\hline & 3,4 & 11 & 101.58 \\
\hline \multirow[t]{3}{*}{5} & 1,6 & 8 & 96.47 \\
\hline & 2,5 & 8 & 96.47 \\
\hline & 3,4 & 8 & 96.47 \\
\hline
\end{tabular}

The resulting effect of this motion causes all draft pads to behave in accordance to second mode shape.

The correlation between the first five mode shapes of an individual draft pad with the first 15 mode shapes and frequencies of the draft gear is summarized in Table 3. It is seen that the first five modes of an individual draft pad have different frequencies when this draft pad coexists with other draft pads in a draft gear. As an example, for an individual draft pad at mode shape 1 the frequency is 77.57 Hz. Column 2 in Table 3 identifies which pads in the draft gear exhibit a similar mode shape, column 3 identifies during which mode shapes of the draft gear this behaviour is observed and column 4 conveys the corresponding frequency value of the draft pads.

Further, the individual draft pad is also subjected to prestress condition before evaluating its modal behaviour. The draft pads are assembled in the draft gear in compressed state, i.e. any draft pad will have a height of $50 \mathrm{~mm}$ which is $17.2 \mathrm{~mm}$ less than the free height of $67.2 \mathrm{~mm}$. The equivalent value of compressive load corresponding to this deflection is estimated to be around $24 \times 10^{3} \mathrm{~N}$. The prestress condition is defined in the form of static load applied on the top plate of the draft pad. These compressive loads give rise to stress field. Once the static analysis establishes the stress field; it can be applied to the draft pad as prestress through options provided in the analysis package. This procedure was repeated for eight different compressive loads till the actual working load was reached. The results for various prestress loads have been summarized and presented in Table 4.

The percent variation in the frequencies for prestress compressive load of the draft pad is plotted in Fig. 5. For an individual draft pad with increase in compressive prestress load the frequency decreases for the first three modes but for the fourth and fifth mode, increase in the compressive prestress load causes increase in the frequency values. The behaviour of the first three modes is in conformance to observations by [9], i.e. with increase in compressive prestress load the frequency decreases, but for the fourth and fifth mode the behaviour is in contract to the observations by [9].

Table 4 Frequency variation of first five modes of draft pad for prestress compressive load

\begin{tabular}{lrrrrrrrr}
\hline Mode no. & \multicolumn{1}{l}{ Modal frequency (Hz) for compressive load } & & & \\
\cline { 2 - 8 } & \multicolumn{1}{c}{$3 \mathrm{kN}$} & $6 \mathrm{kN}$ & $9 \mathrm{kN}$ & $12 \mathrm{kN}$ & $15 \mathrm{kN}$ & $18 \mathrm{kN}$ & $21 \mathrm{kN}$ & $24 \mathrm{kN}$ \\
\hline 1 & 76.78 & 75.84 & 74.80 & 73.70 & 72.53 & 71.30 & 69.99 \\
2 & 101.98 & 100.49 & 98.77 & 96.95 & 95.02 & 92.99 & 90.84 & 88.56 \\
3 & 110.08 & 109.26 & 108.30 & 107.29 & 106.23 & 105.11 & 103.95 & 102.72 \\
4 & 156.60 & 157.98 & 158.94 & 159.73 & 160.38 & 160.90 & 161.30 & 161.58 \\
5 & 198.05 & 200.68 & 202.69 & 204.50 & 206.18 & 207.76 & 209.24 & 210.63 \\
\hline
\end{tabular}




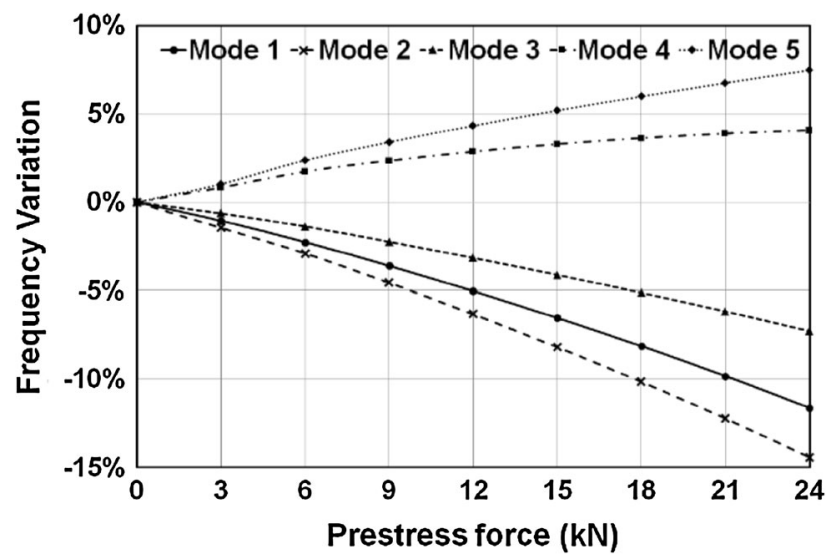

Fig. 5 Frequency variation due to prestress load for various mode shapes

\section{Conclusions}

The mode shapes and frequencies for an individual draft pad and a draft gear have been obtained using finite element approach. It is seen that the mode shapes of draft pads in a draft gear are dominated by the first five modes (Fig. 3) of an individual draft pad. For these dominant mode shapes of an individual draft pad, different values of frequencies (Table 3) of the draft gear have been identified. These values are different than the various values of frequency obtained for an individual pad. These different values of frequency assumes significances as the draft gear is subjected to variable loading frequency due to acceleration and braking of the locomotive. Hence, a range of frequency values have been identified against which a draft pad must be tested for fatigue response. As per the schedule of technical requirements by Indian Railways [13], a draft pad is subjected to cyclic loading of $10 \mathrm{~Hz}$ for determining its fatigue behaviour. The values identified (Table 3) are greater than the existing value but have significance as the possibility that the frequency of cyclic load acting on the draft gear in actual operation will not exceed this specified value cannot be ruled out. The modal analysis thus gives us a basis for subjecting a draft pad to higher frequency loading for determining its fatigue behaviour.

Increase in the value of compressive load on the draft pad shows that not all mode shapes have decreasing values of frequency, due to geometric non-linearity. Of the five modes, only the first three mode shapes show such behaviour. Mode shapes 4 and 5 show increase in frequency with increase in compressive preload. This behaviour is in contrast to the vibrational behaviour exhibited by the first three modes. Since, material non- linearity is neglected during the analyses, such behaviour can be attributed only to two parameters; either the geometric non-linearity or the high Poisson's ratio of rubber compound. It can thus be concluded that geometric nonlinearity and/or high Poisson's ratio can cause the natural frequency of draft pads to increase with increasing compressive preload in case of draft pads (which is a elastomeric material).

Open Access This article is distributed under the terms of the Creative Commons Attribution License which permits any use, distribution, and reproduction in any medium, provided the original author(s) and the source are credited.

\section{References}

1. Polach O, Berg M, Iwnicki S (2006) Simulation. In: Iwnicki S (ed) Handbook of rail vehicle dynamics, 1st edn. CRC Press, Boca Raton, pp 359-422

2. Garg VK, Dukkipati RV (1984) Dynamics of railway vehicle systems. Academic Press, Toronto

3. Duncan IB, Webb PA (1989) The longitudinal behaviour of heavy haul trains using remote locomotives. In: Proceedings of fourth international heavy haul conference, Brisbane, pp 587-590

4. El-Sibaie M (1993) Recent advancements in buff and draft testing techniques. In: Proceedings of IEEE/ASME joint railroad conference, Pittsburgh, pp 115-119

5. Chen O (1998) Dynamic simulation of Taipei EMU train. Veh Syst Dyn 30:143-167

6. McClanachan M, Cole C, Roach D, Scown B (1999) An investigation of the effect of bogie and wagon pitch associated with longitudinal train dynamics. Veh Syst Dyn 33:374-385

7. Cole C, Sun YQ (2006) Simulated comparisons of wagon coupler systems in heavy haul trains. Proc Inst Mech Eng Part F: J Rail Rapid Transit 220:247-256

8. Nasr A, Mohammadi S (2010) The effects of train brake delay time on in-train forces. Proc Inst Mech Eng Part F: J Rail Rapid Transit 224:523-534

9. Bedri R, Al-Nais MO (2005) Prestressed modal analysis using finite element package ANSYS. In: Li Z, Vulkov L, Wásniewski $\mathrm{J}$ (eds) Lecture Notes in Computer Science. Springer, New York, pp 171-175

10. Lu M, Geng H, Yang B, Yu L (2010) Finite element method for disc-rotor dynamic characteristics analysis of gas turbine rotor considering contact effects and rod preload. In: Proceedings of IEEE international conference on mechatronics automation, Xi'an, pp 1179-1183

11. Rao SS (2009) Mechanical vibrations. Pearson Education, New Delhi

12. Harak SS, Sharma SC, Harsha SP (2014) Structural dynamic analysis of freight railway wagon using finite element method. Proc Mater Sci 6:1891-1898

13. Indian Railways Schedule of Technical Requirement No. 55-BD90 for rubber springs of high capacity draft gear for centre buffer couplers of BG Bogie Wagons having $625.5 \mathrm{~mm}$ draft gear pocket, Amendment No. 3, September 1993, pp 1-11 